\title{
Using the visitor-employed photography method to analyse deadwood perceptions of forest visitors: a case study from Bavarian Forest National Park, Germany
}

\author{
Joachim Rathmann ${ }^{1}\left[\right.$ D Philipp Sacher ${ }^{2} \cdot$ Norman Volkmann $^{2} \cdot$ Marius Mayer $^{2} \mathbb{B}$
}

Received: 19 August 2019 / Revised: 13 December 2019 / Accepted: 23 January 2020 / Published online: 3 February 2020

(c) The Author(s) 2020

\begin{abstract}
This study investigates visitors' perceptions and preferences regarding the characteristics of deadwood in the Bavarian Forest National Park (SE-Germany). Visitor-employed photography has been used to collect information about visitors' preferences. Deadwood is the second most photographed forest element which underlines its important role in forest perception. Even though deadwood photographs are evaluated significantly worse than most other forest elements, most visitors nevertheless associate deadwood photographs with a positively rated forest image. Based on the relationship between aesthetics and recreation revealed in the interviews, it can be concluded that the forest path during the hike was both pleasant and restful. This is confirmed by the post-trip interviews, showing that a higher proportion of deadwood is associated with more aesthetics or recreational value. Regarding deadwood structure results show that deadwood fragments and debris are perceived negatively, while root stocks were assessed more positively. We also found a gradient with positive evaluations increasing with progressing decomposition.
\end{abstract}

Keywords Cultural ecosystem services $\cdot$ Deadwood $\cdot$ Forests $\cdot$ Recreation $\cdot$ Visitor-employed photography

\section{Introduction}

Forests provide options for outdoor recreation, to escape from stress, connect with nature and experience tranquil and scenic places (Takayama et al. 2014, Ohe et al. 2017, Taye et al. 2019). Recreation might be the most important non-timber service provided by forests (Elsasser 1996; Meyer et al. 2019). Forest visitors significantly increase

Communicated by Martin Moog.

Joachim Rathmann

joachim.rathmann@uni-wuerzburg.de

Philipp Sacher

philipp.sacher@uni-greifswald.de

Norman Volkmann

norman-volkmann@web.de

Marius Mayer

marius.mayer@uni-greifswald.de

1 Institute of Geography and Geology, Wuerzburg University, Am Hubland, 97074 Würzburg, Germany

2 Institute of Geography and Geology, Universität Greifswald, Friedrich-Ludwig-Jahn-Str. 17a, 17487 Greifswald, Germany their well-being by several factors (Wallner et al. 2018). Additionally, tourism can trigger considerable income for communities adjacent to larger forests (Job 2008; Mayer and Woltering 2017). Thus, forest aesthetics is a relevant factor for recreation purposes, which can be influenced by forest management (Nielsen et al. 2007). Foresters frequently regard deadwood as a threat to forests, which can trigger fires, insect attacks or pests (Paletto et al. 2012). Therefore, deadwood is usually removed from forests in traditional silvicultural management (Pastorella et al. 2016).

The term deadwood refers to all non-living woody biomass not contained in the litter (Paletto and Tosi 2010), either standing, lying woody debris or pile wood volumes on the ground or in the soil, including logs, dead trunks, fallen branches, fallen twigs, dead roots and stumps. The two main components of deadwood are standing dead trees (snags) and lying deadwood (logs). Both have different ecological functions and serve as habitat for different organisms (Müller and Bütler 2010; Humphrey and Bailey 2012). In recent years, the awareness of deadwood as an extremely valuable source for biodiversity has risen as deadwood is essential for several ecological processes within forest ecosystems (e.g. Garbarino et al. 2015; 
Seibold et al. 2016). Despite many studies dealing with the ecological importance of deadwood, only few studies analyse visitors' perception of deadwood so far (Pastorella et al. 2016; Sacher et al. 2017).

Old trees and deadwood due to ageing processes may be perceived negatively. Deadwood on the ground may not be appreciated by the public, as it is claimed to reduce scenic beauty and might even lower recreational values of forests, resulting in subsequent deadwood removal (e.g. Tyrväinen et al. 2003; Edwards et al. 2012a, b; Hauru et al. 2014). Brown and Daniel (1986) showed negative correlations of scenic beauty estimates and downed wood in timber stands. According to Golivets (2001), the presence of deadwood is one important factor leading to negative attitudes about forests. Moreover, large branches falling from trees are unquestionably a hazard for public safety and may thus be perceived as dangerous (Carpaneto et al. 2010). Paletto et al. (2017) underline that visitors prefer managed forests based on interviews in a peri-urban forest in Tuscany (Italy), while Sacher et al. (2017) show that visitors in Harz National Park, Germany, largely oppose to the idea of removing dead trees from the park in contrast to a sample of the local population (von Ruschkowski and Mayer 2011). Müller and Job (2009) examined tourists' attitude towards large-scale bark beetle infestations leading to huge amounts of deadwood in the Bavarian Forest National Park, Germany, showing that tourists have, on average, a neutral attitude towards the bark beetle, whereas Arnberger et al. (2018) reveal that forest visitors dislike substantial amounts of deadwood in forests. However, added information on ecological processes within deadwood-rich forests can increase public support for corresponding forest management strategies (Gundersen et al. 2017). Again, the local tourism operators in the municipalities adjacent to the Bavarian Forest National Park showed a rather polarized attitude towards the effect of deadwood on tourism (von Ruschkowski and Mayer 2011), which only improved slightly since then (see Job et al. 2019).

However, visitors' perception of deadwood might influence their appreciation of scenic forest sites, and therefore its recreational benefits. Thus, our study aims to thoroughly analyse forest visitors' association with deadwood to improve forest management strategies and resolve potential conflicts and trade-offs in deadwood-related forest ecosystem services. Therefore, the main objective of the present study is the visual-based analysis of forest visitors' perception of deadwood along a hiking trail in the Bavarian Forest National Park, SE-Germany. We test these prevailing assumptions of negative influences of deadwood on the recreational experience in forests by applying the visitor-employed photography (VEP) method. This method is appropriate in this context as deadwood is part of overall forest aesthetics. The visual appearance of forests is of great importance as people experience their environment initially visually, and aesthetics is the most fundamental dimension of people-landscape interactions (Kaplan and Kaplan 1989).

This article is structured as follows: After a brief description of the VEP method, we explain our data collection and analyses followed by the results. The contribution finishes with a discussion and conclusions for research and forest practice.

\section{Visitor-employed photography}

Many studies on landscape assessment are based on photographs (Mackay and Couldwell 2004; Levine and Jensen 2007; Qiu et al. 2013), but only few of them apply VEP. This method uses participants' own photographs to assess perceptions, experiences and interpretations of their environment and was first introduced by Cherem (1973). With the development of modern photographic technologies, VEP gains importance in investigating visitors' experiences, without redefining these by researchers' instructions (Taylor et al. 1995; Dakin 2003).

VEP has been widely used in recreational contexts, as it allows an effective, fast measurement of on-site and realtime responses, making it applicable to a variety of field situations, especially linear situations such as rivers, trails and roads (Oku and Fukamachi 2006; Dorwart et al. 2007). For instance, Gou and Shibata (2017) used the VEP supplemented with interviews to study the visitor experience on a pilgrimage route in Japan. It was also applied to evaluate tourists' destination images (MacKay and Couldwell 2004) and to assess the opinions regarding problems in tourism planning (Balomenou and Garrod 2014). Lee and Son (2017) use VEP to directly explore on-site landscape perceptions of the Bukhansan National Park, South Korea, among two groups. However, in a central European context VEP has been used rarely so far, especially focussing on forests.

VEP aims to figure out how the contextual meaning of landscapes contributes to visitors' overall experience. The results illustrate how attributes of landscape elements and spatial configurations influence this experience. One major advantage of VEP is its explorative character as a free association method. VEP was adopted to allow new categories to "emerge" inductively from the data. When supplemented by interviews, it provides an opportunity to combine perceptions, emotions and other subjective feelings related to physical landscape attributes and their spatial configuration for an examination of the direct, on-site experience of the visitors (Lee and Son 2017). This is a considerable difference to other approaches of photograph elicitation, being widely used for landscape assessment studies and scenic beauty studies (Loeffler 2004). 


\section{Materials and methods}

Aesthetic experience consists of different perceived components which can be classified as multisensory intuitive experience, coherence, aesthetic diversity, biodiversity, restorativeness and order (Hauru et al. 2014). Nevertheless, some studies show that it is not possible within the framework of the VEP to grasp the stimuli going beyond visual aspects adequately. Thus, in addition to the visual impression, odours, noises and tangible stimuli such as the weather can have an influence on the evaluation of a scene (Oku and Fukamachi 2013; Dorwart et al. 2007). In this context, however, some researchers also emphasize that nonvisual stimuli are already included in the evaluation during the VEP process, and that the resulting photographs are, so to speak, a documentation of experiences at all sensory levels (Qiu et al. 2013). For this reason, it makes sense to have the photographs taken commented by the participants in addition.

\section{Survey Design}

Our study uses the VEP "triad" described in Balomenou and Garrod (2014) as methodological approach. The triad consists of the following elements: (1) we gave participants digital cameras to take their photographs. 2) On their trail, we provided them with a photolog to note the key features of each photograph (what they believed it to contain) and what positive and negative emotions they associate with this view. ${ }^{1}$ (3) We asked participants for socio-demographic data and attitudinal questions in post-trip interviews after returning the camera. As most visitors were walking in groups, we interviewed only the person who actually used the camera. The interview was semi-structured, using 17 open and closed questions, providing data directly linked to the visitors' photographs. The first part consists of general questions about forests. Visiting frequencies and motivations, associations with forests and the photographs were recorded. The question of whether something special was noticed on the forest path led to the second part, where we asked about the respondents' attitudes towards deadwood and their evaluation of their overall experience using five-point Likert scales.

Data were collected during a 5-day period in August 2016, were we randomly selected forest visitors on a highly frequented trail in the Bavarian Forest National Park called "Schwellsteig" and equipped them with digital cameras (Nikon Coolpix S33, an easy to use digital camera with 13 megapixel). The weather during the survey was mixed

\footnotetext{
1 The emotions captured in the process allowed us to draw conclusions about the overall experience of the participants, but due to the scope of the analysis they cannot be presented here.
}

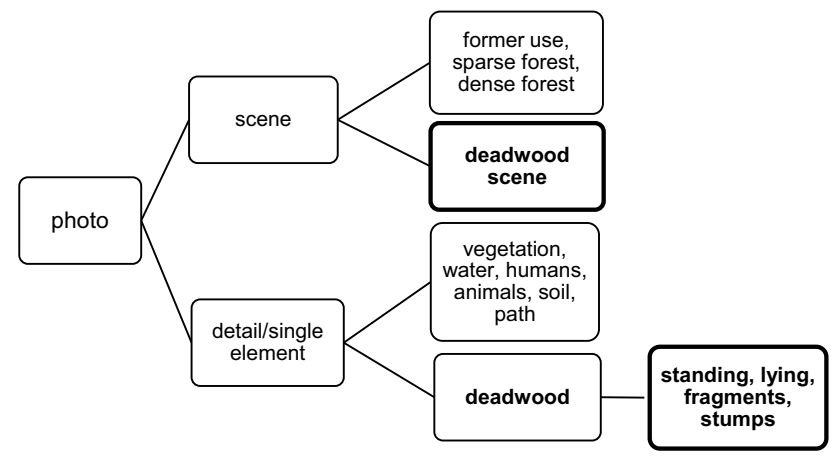

Fig. 1 Photograph classification scheme

and ranged from rainy days to sunny conditions. We asked the participants to take a maximum of ten pictures of forest items they like or dislike along the trail. No specifications about these items or the share of liked or disliked pictures were made. For each picture, we asked them to record key elements of the photography (what was in focus) and their related emotions in short words in the photolog. It is important to note that the chosen study area is located in the development zone of the National Park. For this reason, the forest structures that the participants were confronted with are already more natural than in conventionally used commercial or peri-urban recreational forests. Accordingly, the proportion of deadwood along the trail is also higher than in average German forests. However, traces of past forestry use are still to be found here, so that it will still take a long time until this part of the park could be described as natural forest.

\section{Photograph classification}

After removing duplicates and excess, the present study uses 962 photographs and 118 valid final interviews. The classification of the photographs is based on Kaplan and Kaplan (1989), Oku and Fukamachi (2006), Heyman (2012), Nielsen et al. (2012) and Qiu et al. (2013). The photograph classification scheme (Fig. 1) shows two superordinate topics. Kaplan and Kaplan (1989: 26) describe them as "content configuration" and "spatial configuration", where "content"based photographs have in common that they always show specific objects or elements, while "spatial configurations" show a distribution of elements or objects in the scene.

Photographs have been labelled as "group of scenes" when several elements such as similar sized trees dominated the picture and when the entries in the photolog indicated that there was no particular element in the focus. The assignment of a photograph to the group of elements was more complicated. In addition, we identified only two elements representing human influence, namely the path and other signs of human activities (e.g. waste), although other 
Fig. 2 Examples of visitor photographs with deadwood and photolog entries. $\mathrm{D}^{\circ} 1-4$ refers to the decomposition grades, with the following levels: $\mathrm{D}^{\circ}$ $1=$ freshly dead $; \mathrm{D}^{\circ} 2=$ starting decomposition; $\mathrm{D}^{\circ} 3=$ advanced decomposition; $\mathrm{D}^{\circ} 4=$ highly decomposed/rotted. Source: own research

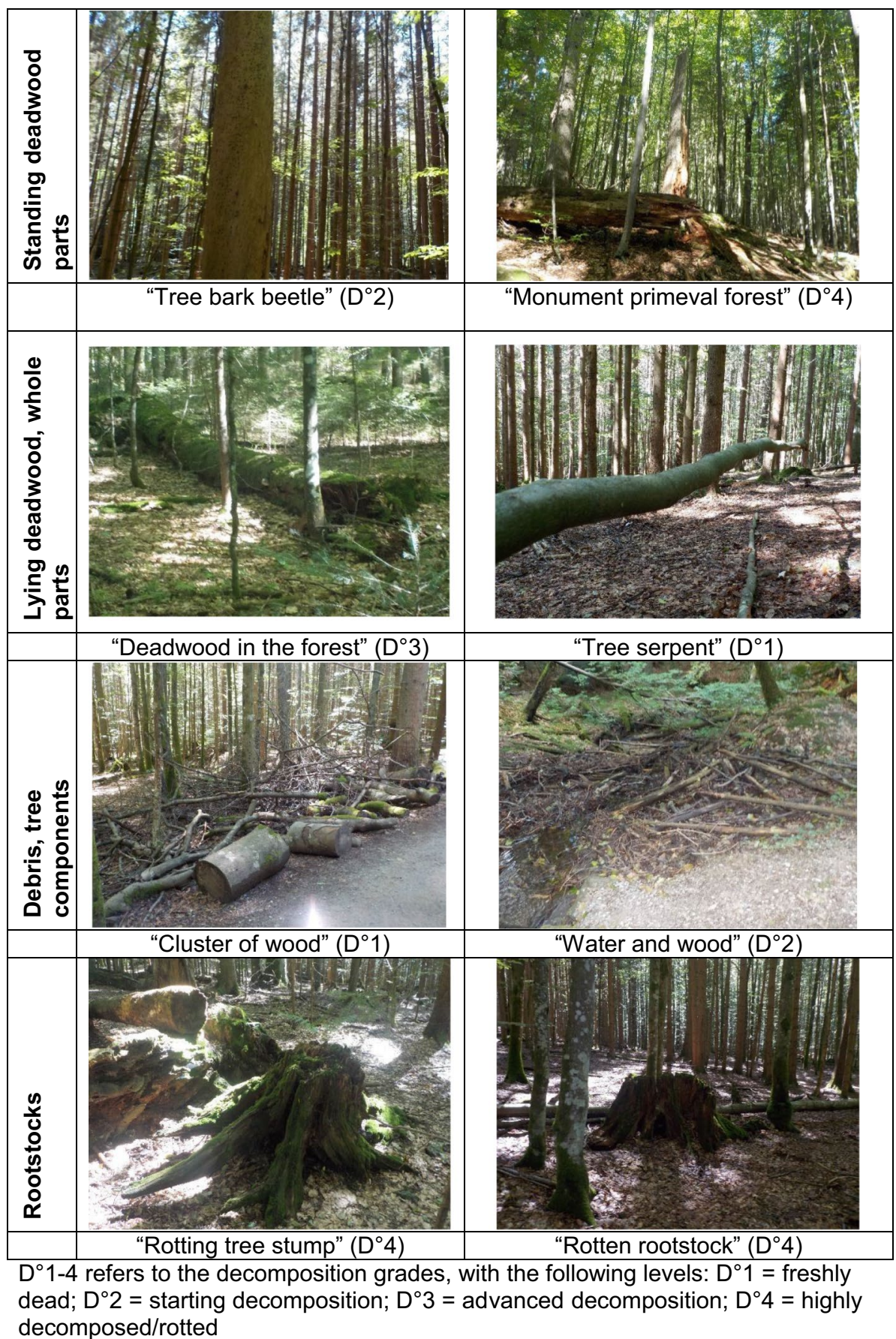

elements such as still visible former forest paths may well have experienced human influence before as well.

In contrast to the other landscape elements, deadwood was classified according to further characteristics. The prerequisite was a clearly recognizable deadwood biomass in the photograph and a reference to it in the photolog. A distinction was made between the form and the degree of decomposition. Figure 2 shows examples of photographs taken by the participants framed into our classification scheme.
In order to determine the relationship between deadwood perception and photograph rating, correlation analyses and a binary logistic regression model were calculated. The logistic regression model seems appropriate as the evaluation of the photographs uses a dichotomous dependent variable with the two levels "liked" and "disliked", while the explanatory variables used were subject-specific parameters. Since it was a repeated observation for a forest visitor, its variable values were also repeated for each 
Fig. 3 Deadwood associations of the visitors according to the question "How much do you agree that the following aspects are related to a higher deadwood share?". Source: own research

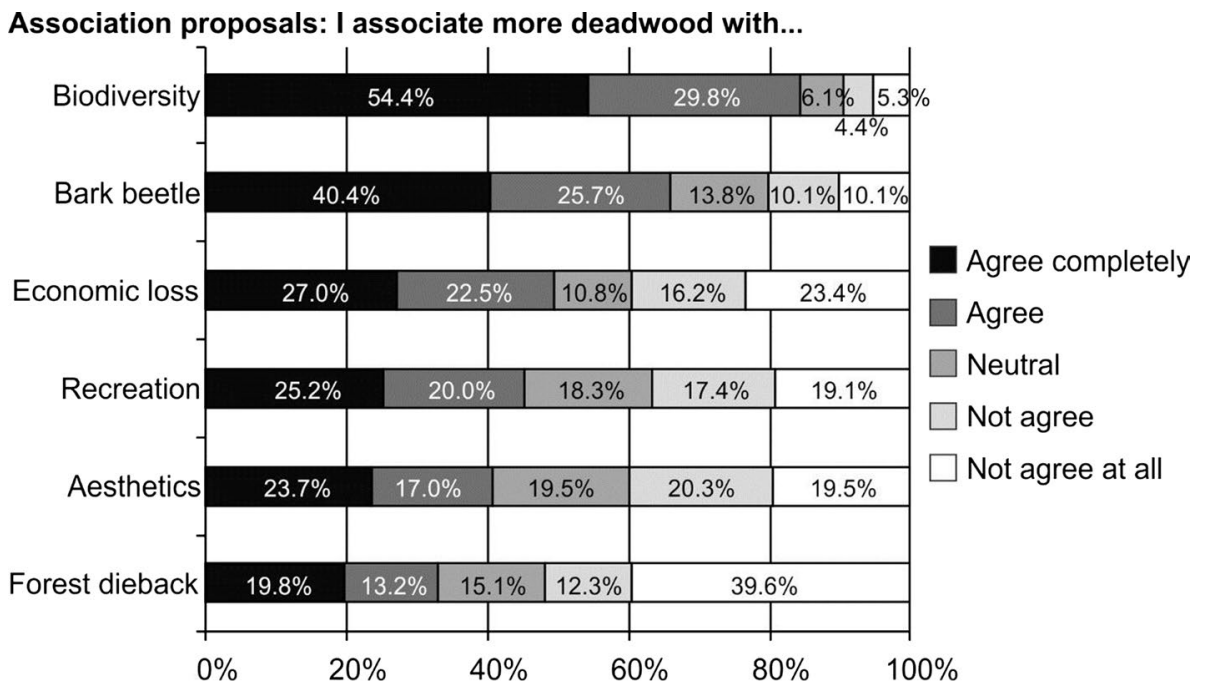

rating, increasing the number of observations to the number of photographs (long-format data).

\section{Results}

\section{Socio-demographic characteristics of the sample}

125 forest visitors participated in the study. The age spectrum of the respondents ranges from 12 to 76 years with an average age of 48.5. 59 persons interviewed were male (47.2\%) and 49 (39.2\%) female. In 17 cases, no assignment was possible, since the main interviewee could not be clearly defined. (Often there was more than one speaker in a group.) $19.2 \%$ of the visitors came from the direct vicinity of the National Park, with distances of less than $30 \mathrm{~km} .62 .7 \%$ of the respondents indicated to have grown up in rural areas, $15.9 \%$ in partially urban and $14.3 \%$ in urban areas $(7.1 \%$ no answer).

The level of education among the participants was very high. Every second (53.2\%) has a university degree or passed a university entry examination. Only a minority of $13.6 \%$ deal privately or commercially with biodiversity. It is important to mention that the sample is not representative for the Bavarian population, as a high proportion of respondents from a rural area participated and the proportions of families with children and higher educated people were very high.

\section{Forest perceptions of visitors}

A large majority of the respondents visits forests more often than once a month. $69.2 \%$ stated that they visited forests at least several times a month. We also asked the respondents about their associations with forests. The most common association with forests is recreation (72\%), followed by the general term "nature" (50\%). Activities (such as walking) were also frequently associated (19.5\%). The connection of such activities with the topic "forest" has an even higher priority than "fresh air" (12.7\%).

The most important motivation for visiting the hiking trail was the "Schwellhäusl", a small forest restaurant at the end of the hiking trail, typical for the region, which was named by about a third of the respondents. The second most important motivation is "tradition". The term "tradition" has linked all answers that imply regularity, e.g. "We come here every summer". Activities and recreation, which often refer to forest associations, are also important motivations. We asked the respondents to rate the trail they just hiked. Nearly $90 \%$ rated it with at least "good" (average of 1.6 on a five-point Likert scale from one = very good to five $=$ very bad; $\mathrm{SD}=0.8$ ).

After documenting their association with deadwood, the participants obtained some suggestions by the interviewer. Participants had the opportunity to express their attitudes towards them on a five-point Likert scale (Fig. 3).

The associations of the respondents towards deadwood can be described as heterogeneous. Most of the respondents see a strong connection between deadwood and biodiversity as $84.2 \%$ completely agree or agree with this statement. Bark beetles are more likely to be associated with a higher proportion of deadwood ( $66.1 \%$ completely agree or agree), while forest dieback is rather not (more than $50 \%$ do not agree). The visitors rather agree that deadwood is linked to economic loss (49.5\% agree vs. $39.6 \%$ disagree). $40.7 \%$ of the visitors associate aesthetical value with higher deadwood share and even more, $45.2 \%$, assume that more deadwood is associated with recreation. In contrast, similarly large groups $(39.8 \%$ for aesthetics and $36.5 \%$ for recreation) do not relate these attributes to more deadwood, which indicates both a quite high level of uncertainty among the respondents but also underlines the ambivalent evaluation of deadwood. 
Table 1 Correlations between statements about consequences of higher deadwood shares (spearman rho coefficients). Source: own survey

\begin{tabular}{|c|c|c|c|c|c|c|c|c|c|}
\hline & 1 & 2 & 3 & 4 & 5 & 6 & 7 & 8 & 9 \\
\hline (1) Percentage of positively valued deadwood photographs & 1.00 & & & & & & & & \\
\hline (2) Aesthetics and higher deadwood share & $-0.48 * *$ & 1.00 & & & & & & & \\
\hline (3) Recreation and higher deadwood share & $-0.34 * *$ & $0.69 * *$ & 1.00 & & & & & & \\
\hline (4) Occupation (private or commercially) with deadwood & -0.11 & $\mathbf{0 . 2 5} * *$ & $\mathbf{0 . 3 0} * *$ & 1.00 & & & & & \\
\hline (5) Biodiversity and higher deadwood share & $-0,15$ & $0.22 *$ & $0.22 *$ & $0.22 *$ & 1.00 & & & & \\
\hline (6) Economic disadvantage and higher deadwood share & 0.00 & -0.10 & -0.05 & -0.01 & 0.02 & 1.00 & & & \\
\hline (7) Bark beetle and higher deadwood share & 0.00 & $-0.20 *$ & -0.13 & 0.00 & 0.00 & $\mathbf{0 . 2 8} * *$ & 1.00 & & \\
\hline (8) Forest dieback and higher deadwood share & 0.05 & $-0.26 * *$ & $-0.26 * *$ & 0.07 & $-0.32 * *$ & $0.23 *$ & $0.39 * *$ & 1.00 & \\
\hline (9) Did you like the trail & -0.01 & $0.25 * *$ & 0.14 & -0.02 & -0.16 & $-\mathbf{0 . 2 8} * *$ & -0.05 & 0.01 & 1.00 \\
\hline (10) With less deadwood I would have liked the trail more & $0.28 * *$ & $-\mathbf{0 . 3 8} * *$ & $-\mathbf{0 . 3 2} * *$ & 0.10 & -0.12 & 0.12 & $0.21 *$ & 0.10 & -0.04 \\
\hline
\end{tabular}

The scales for the items were the following

(2), (3), (5)-(6) and (10): from $1=$ "very much agree" to $5=$ "highly disagree"

(4): from $1=$ "very often" to $5=$ "very rarely"

(9): from $1=$ "enjoyed it very much" to $5=$ "disliked it very much"

$* p<0.05 ; * * p<0.01$

Bold numbers indicate statistically significant results

Focusing on deadwood perception, visitors were asked whether a smaller amount of deadwood would increase their preference for the forest path. $65.5 \%$ reject this statement. A quarter (25.2\%), however, indicated that a lower amount of deadwood would have improved their experience along the trail.

A correlation analysis of these statements with the relative share of positively rated deadwood photographs per respondent shows a correlation of medium strength between deadwood perception and aesthetics $(-0.48 ; p<0.01$; negative sign due to inverse scaling) and recreation $(-0.34 ; p<0.01)$ associations (Table 1). That means, the more positive respondents' attitudes towards deadwood, the more positive also their aesthetic evaluation of photographs depicting deadwood. There is also a strong positive correlation between the associations of aesthetics and recreation with higher deadwood amounts $(0.69 ; p<0.01)$. That means, those respondents who ascribe a positive aesthetic value to deadwood also state that it is positive for recreation and vice versa. In contrast, when the participants stated to prefer less deadwood on the hiking trail, they tended to rate deadwood photographs more negatively $(0.28 ; p<0.01)$.

Those respondents who associate forest dieback with higher shares of deadwood do rather not associate aesthetics, recreation and biodiversity with more deadwood, as indicated by the negative correlations in Table 1. In turn, the association of biodiversity is positively correlated to both associations of aesthetics and recreation.

\section{Valuation of the photographs}

\section{Photograph classification}

On average, every respondent took 7.7 photographs. The overall valuation of the 965 pictures in the photologs was positive, as almost $69 \%$ of the photographs have been classified as "liked" (Table 2). 17.3\% of the pictures show forest scenes, $64.6 \%$ of them are liked. $7.5 \%$ depict deadwood scenes, which were rated worst ( $45.8 \%$ liked); even worse than traces of former human use such as old skid trails. However, the scenes with deadwood clearly outweighed (72) the small number of photographs showing former use (16).

The elements from the landscape catalogue account for $81.7 \%$ of the pictures taken and are evaluated positively by $69.4 \%$-no statistically significant differences can be found to the evaluation of the scenes. On average, visitors made 6.4 photographs of individual elements. Most frequently photographed were living vegetation, deadwood and signs of human activities. Animals or the path have been photographed rarely. Considering an equal distribution of the photographed forest elements, it is obvious 
Table 2 Overview of photograph classification and evaluation. Source: own research

\begin{tabular}{lcccll}
\hline Photograph class & $\begin{array}{l}\text { Share of photograph class } \\
\text { among all 965 photographs in } \%\end{array}$ & $\begin{array}{l}\text { Total } \\
\text { amount } \\
\text { liked }\end{array}$ & $\begin{array}{l}\text { Total amount } \\
\text { disliked }\end{array}$ & \% liked & Sum \\
\hline Forest scene & $\mathbf{1 7 . 3}$ & & & $\mathbf{6 4 . 6}$ & $\mathbf{1 6 7}$ \\
Closed forest & 15.9 & 105 & 48 & $68.6 \mathrm{a}, \mathrm{b}$ & 153 \\
Open forest & 0.9 & 9 & 0 & 100.0 & 9 \\
Former use & 1.7 & 8 & 8 & 50.0 & 16 \\
Deadwood scene & 7.5 & 33 & 39 & $45.8 \mathrm{a}$ & 72 \\
Forest element & $\mathbf{8 2 . 7}$ & & & $\mathbf{6 9 . 4}$ & $\mathbf{7 9 8}$ \\
Vegetation & 26.3 & 233 & 21 & $91.7 \mathrm{a}, \mathrm{b}$ & 254 \\
Deadwood element & 15.6 & 151 & 93 & $61.9 \mathrm{~b}$ & 244 \\
Human activity & 13.1 & 31 & 95 & $24.6 \mathrm{~b}$ & 126 \\
Water & 7.0 & 62 & 6 & $91.1 \mathrm{a}, \mathrm{b}$ & 68 \\
Soil & 5.1 & 47 & 2 & $95.9 \mathrm{a}, \mathrm{b}$ & 49 \\
Animals & 3.0 & 19 & 10 & 65.5 & 29 \\
Path & 2.9 & 22 & 6 & $78.6 \mathrm{a}, \mathrm{b}$ & 28 \\
Photolog total & & & & $\mathbf{6 8 . 9}$ & $\mathbf{9 6 5}$ \\
\hline
\end{tabular}

Among scenes, double allocations were possible

Bold elements indicate the overarching terms of the photograph classification scheme (Fig. 1)

Elements sharing a letter are statistically significant according to ANOVA Tamhane post hoc tests at least at the $p<0.05$ level. For the sake of readability, we only depict the significances for the two deadwood variables in this table

Table 3 Classification of deadwood in the photographs after class and decomposition grade. Source: own research

\begin{tabular}{|c|c|c|c|c|c|c|}
\hline . & Photograph class & $\begin{array}{l}\text { Share of deadwood elements } \\
\text { among all photographs in \% }\end{array}$ & Liked & disliked & $\%$ liked & sum \\
\hline & Deadwood (elements and scenes) & 32.8 & 181 & 136 & 57.1 & 317 \\
\hline & Standing trunks & 5.0 & 27 & 21 & $56.3 \mathrm{a}$ & 48 \\
\hline \multirow[t]{4}{*}{ Deadwood class } & Lying trunks & 12.6 & 72 & 50 & $59.0 \mathrm{~b}$ & 122 \\
\hline & Debris/fragment & 10.3 & 37 & 62 & $37.4 \mathrm{a}, \mathrm{b}$ & 99 \\
\hline & Rootstocks & 5.0 & 45 & 3 & $93.8 \mathrm{a}, \mathrm{b}$ & 48 \\
\hline & Fresh deadwood & 4.2 & 19 & 22 & $46.3 \mathrm{c}, \mathrm{d}$ & 41 \\
\hline \multirow[t]{3}{*}{ Decomposition grade } & Beginning decomposition & 15.6 & 73 & 78 & $48.3 \mathrm{e}, \mathrm{f}$ & 151 \\
\hline & Advanced decomposition & 5.3 & 36 & 15 & $70.6 \mathrm{c}, \mathrm{e}$ & 51 \\
\hline & Highly decomposed & 6.0 & 47 & 11 & $81.0 \mathrm{~d}, \mathrm{f}$ & 58 \\
\hline
\end{tabular}

Elements sharing a letter are statistically significant according to ANOVA Tamhane post hoc tests at least at the $p<0.05$ level

that deadwood played an important role as a motive for the visitors. The evaluation ranges from $24.6 \%$ liked for human traces up to $95.9 \%$ for forest soil. The fact that pictures showing human impacts were evaluated negatively is because the most common human impact motif was trash. All other elements are more connected to a well-liked forest image than to a disliked one. Deadwood which appears on 244 photographs showing forest elements $(25.3 \%$ of all photographs; $30.6 \%$ of forest elements) is rated second worst among elements $(61.9 \%$ of deadwood elements were liked) and about $30 \%$ worse than living vegetation, which is depicted on 254 photographs. However, it also tends to be an element of a preferred forest image as more than half of the pictures showing it are rated as "liked".

\section{Deadwood valuation in the photographs}

We examined the forest attribute deadwood separately by grouping it into the three classes: deadwood class (four levels: standing trunks, lying trunks, debris/fragments, 
rootstocks), wood type (coniferous, broad leaf) and decomposition grade (Table 3 ).

Overall, deadwood appears in $32.8 \%$ of all photographs. Lying trunks $(12.6 \%)$ and fragments $(10.3 \%)$ were twice as often on a photograph compared to standing deadwood elements or rootstocks (5.0\% each). However, different deadwood structures were present in different quantities along the hiking trail, so that the determined deviations can also be explained by them. The majority of the visible deadwood was formed by fallen and abandoned trees, whereas dead but upright trunks were much rarer. The evaluations are also notably different. Visitors made the biggest aesthetic difference between rootstocks (93.8\% liked) and fragments (37.4\%). Whole trunks, lying (59\%) or standing (56.3\%), are rated almost identically with no statistically significant differences in contrast to all other combinations.

Elements in beginning decomposition (15.6\%) were photographed nearly three times as often as elements of the other degrees of decomposition. It is evident that there is a valuation gradient between the different decomposition grades: Deadwood in the fresh state $(46.3 \%$ liked) and in beginning decomposition (48.3\%) is valuated significantly much worse than advanced $(70.6 \%)$ and high $(81 \%)$ decomposition. The visitors obviously prefer the latter conditions.

\section{Influence of photograph- and respondent-related factors on deadwood valuation}

Finally, we estimated a binary logistic regression model that included the dichotomous evaluation of each photograph as dependent variable, to gain deeper insights into the influences of sample-specific variables on the photograph evaluation. Due to the long-format structure of the data used for the model, the influence of a large number of variables, which relate not only to the individual respondents but also to each single photograph, can be examined.

In the first partial model, we examined the relationship between deadwood as a motif and the photograph evaluation for all photographs. Results show that there is a significant influence of the fact that a photograph shows deadwood on the probability of a negative rating of the photograph (beta 0.765, $\operatorname{Exp}(\mathrm{B}) 2.149, p<0.001$; 0: no deadwood, 1: deadwood). As in the descriptive analysis, deadwood photographs tend to be among the more negatively rated objects. The same models conducted only for photographs showing forest elements, respectively, scenes led also to a highly significant negative influence of deadwood pictures, but with a weaker regression coefficient of beta $0.594(\operatorname{Exp}(B) 1.811$, $p<0.001$ ) for elements and a stronger value for scenes (beta $1.429, \operatorname{Exp}(\mathrm{B}) 4.174, p<0.001)$.

In contrast, regarding all photographs we found out that compared to all other motif categories neither deadwood as an element nor as a scene has a significant influence on the rating. (While vegetation, closed forests, water, soil and trail have a significant positive influence, human traces a negative influence.)

Taking the deadwood structure and decomposition grade as independent variables, we see that fragments and rootstocks both exert a significant influence on the rating, which is negative for the fragments (beta 1.265, $\operatorname{Exp}(\mathrm{B})$ $3.541, p<0.01$ ) and positive for the rootstocks (beta $-1.726, \operatorname{Exp}(\mathrm{B}) 0.178, p<0.05)$. Compared to fresh deadwood, advanced (beta $-1.749, \operatorname{Exp}(\mathrm{B}) 0.174, p<0.001$ ) and high (beta $-1.110, \operatorname{Exp}(\mathrm{B}) 0.330, p<0.1$ ) decomposition grades have a positive influence on the probability of a positive rating of the photograph.

By adding socio-demographic characteristics of the respondents, we built up an overall model for testing the influence of both photograph- and respondent-related variables on the evaluation of the photographs, showing deadwood only (Table 4). Since deadwood-related variables have been included in the model, only those photographs were taken into account that showed it $(n=311)$. Due to missing values, the final number of cases was reduced again to 157 . This explains the often only small significance levels, which nevertheless point to the essential influences: The most significant influence among the photograph-related attributes is that of photograph classification, i.e. whether it is a scene or an element. Thus, the presence of deadwood elements increases the probability of a positive photograph evaluation compared to deadwood scenes (which could not be confirmed for all photographs).

Interestingly, the deadwood structures seem to have no significant influence in this model, even if the trends already identified in the descriptive evaluation are confirmed. (Deadwood debris tends to be evaluated worse than other stands with standing trunks as reference.) For the degree of decomposition, we confirm the gradient identified in the section above: The evaluation improves with increasing decomposition, but this influence is statistically significant only for the advanced decomposition grade (fresh deadwood as reference here).

Looking at the socio-demographic factors, we recognize a significant influence of age on the rating. Elderly people slightly tend to rate deadwood more positively. Also, the net household income of the respondents seems to exert an influence with more affluent respondents having a higher probability of positive deadwood photograph evaluations. However, this result is only statistically significant for the income category between 3000 and 4000 Euro. The significant effect of gender contradicts the findings from the $t$ test conducted with the interview items showing that men tend to associate deadwood more with aesthetics than women do-the result in Table 4 indicates the contrary. 
Table 4 Coefficients and model statistics of the binary logistic regression with photograph valuation as dependent variable. Source: own survey

\begin{tabular}{|c|c|c|c|c|}
\hline Independent variables & $\begin{array}{l}\text { Regression coef- } \\
\text { ficient }\end{array}$ & SE & Wald & $\operatorname{Exp}(B)$ \\
\hline $\begin{array}{l}\text { Photograph class }(1=\text { element, } 2=\text { scene }) \\
\text { Deadwood class } \\
\text { [standing] }\end{array}$ & $2.432 * *$ & 0.864 & $\begin{array}{l}7.925 \\
4.958\end{array}$ & 11.385 \\
\hline Lying $(1=$ yes, $0=$ no $)$ & -0.434 & 0.875 & 0.246 & 0.648 \\
\hline Debris $(1=$ yes, $0=$ no $)$ & 1.109 & 0.907 & 1.496 & 3.032 \\
\hline $\begin{array}{l}\text { Rootstocks }(1=\text { yes, } 0=\text { no }) \\
\text { Decomposition grade } \\
\text { [Fresh] }\end{array}$ & -1.461 & 1.821 & $\begin{array}{l}0.644 \\
6.107\end{array}$ & 0.232 \\
\hline Beginning decomposition $(1=$ yes, $0=$ no $)$ & -0.853 & 0.715 & 1.425 & 0.426 \\
\hline Advanced decomposition $(1=$ yes, $0=$ no $)$ & $-2.337^{*}$ & 1.063 & 4.837 & 0.097 \\
\hline Highly decomposed $(1=$ yes, $0=$ no $)$ & -2.749 & 1.760 & 2.438 & 0.064 \\
\hline Age of respondent & $-0.097^{*}$ & 0.041 & 5.499 & 0.908 \\
\hline $\begin{array}{l}\text { Gender }(0=\text { female, } 1=\text { male }) \\
\text { Income } \\
{[<1000 €]}\end{array}$ & $1.519 *$ & 0.709 & $\begin{array}{l}4.590 \\
6.652\end{array}$ & 4.569 \\
\hline 1000 to $<2000 €(1=$ yes, $0=$ no $)$ & -0.893 & 1.649 & 0.293 & 0.410 \\
\hline 2000 to $<3000 €(1=$ yes, $0=$ no $)$ & -1.944 & 1.477 & 1.733 & 0.143 \\
\hline 3000 to $<4000 €(1=$ yes, $0=$ no $)$ & $-2.869^{\#}$ & 1.469 & 3.813 & 0.057 \\
\hline 4000 to $<5000 €(1=$ yes, $0=$ no $)$ & -0.999 & 1.650 & 0.366 & 0.368 \\
\hline$>5000 €(1=$ yes, $0=$ no $)$ & -2.270 & 1.455 & 2.435 & 0.103 \\
\hline Group size & -0.223 & 0.209 & 1.145 & 0.800 \\
\hline Number of children & $-0.632^{\#}$ & 0.360 & 3.080 & 0.532 \\
\hline Constant & $5.668^{*}$ & 2.446 & 5.370 & 289.504 \\
\hline
\end{tabular}

Dependent variable: $1=$ liked, $2=$ disliked; $* *<0.01$, ${ }^{*} p<0.05,{ }^{\#} p<0.1$; model parameters: -2 Log-Likelihood $=91.558$, Cox and Snell $R^{2}=0.370$, Nagelkerke's $R^{2}=0.504,82.1 \%$ of pictures correctly classified

Bold numbers indicate statistically significant results
The number of own children is related to a more positive evaluation of deadwood photographs.

Finally, we found no significant influence of the different weather conditions during the survey days on quantity and valuation of photographs with deadwood motives, according to ANOVA and post hoc tests.

\section{Discussion and conclusions}

The present study analyses forest visitors' associations with deadwood based on the VEP approach with 125 forest visitors participating. Balomenou and Garrod (2016) assume a mean of 113.2 participants after comparing almost 300 studies where the method was applied. But generally, VEP data sets have, as an initially qualitative research method, typically rather small case numbers, e.g. 33 participants (Dorwart et al. 2010), 62 (Heyman 2012) or 69 (Qiu et al. 2013). Thus, the present study is more comprehensive than previous ones.

The fact that the individual elements make up the vast majority of generated photographs (798 out of $965 ; 82.7 \%$ ) is typical for VEP since similar studies reveal comparable results (Qiu et al. 2013). It is remarkable that deadwood ranks second among the elements in the photolog. Together with the 72 photographs of the deadwood scenes, it is the strongest perceived forest attribute, occurring on 316 photographs. This might be partly due to the general forest structure in the research area strongly influenced by its national park status, while other reasons for the numerical dominance of deadwood photographs might be a kind of fascination for deadwood structures.

Visitors' associations with deadwood are similar to the results by Wagner and Suda (2008) but an important new association could be revealed: "a place to live", habitat. $26.4 \%$ of the participants' associations could be classified under this category (items like "lots of beetles", "biodiversity", etc.). Most visitors associate deadwood photographs with a positively rated forest image. However, based on the relationship between aesthetics and recreation revealed in the interviews, it can be concluded that the forest path during the hike was both pleasant and restful. This is confirmed by the post-trip interviews, showing that the respondents associate a higher proportion of deadwood with more 
aesthetics or recreational value. This conclusion raises questions if higher amounts of deadwood do not negatively affect the aesthetic experience and the recreational value. Thus, increasing deadwood amounts for ecological purposes do not necessarily raise conflicts with recreationists in forests. This means that forest management strategies can focus on deadwood accumulation even in highly frequented forest sites. However, it could also be the case that the respondents implicitly ascribe the survey area a higher recreational value due to its national park status which in turn is related to the significantly higher share of deadwood compared to commercially managed forests.

Despite the positive evaluation of the deadwood photographs, deadwood elements and scenery are on average rated worse than the other photograph-documented forest characteristics. This implies that deadwood remains a contested forest element which leads to ambivalent, partly even polarized perceptions and reactions of forest visitors. This is in line with earlier results by Müller et al. (2008), Müller and Job (2009) or Sacher et al. (2017) from other German national parks but also corresponds to results from park-people relationship studies (von Ruschkowski and Mayer 2011; Job et al. 2019).

However, the different types of deadwood are also assessed differently. In particular, deadwood fragments and debris are perceived negatively. If these elements occur more frequently, the entire deadwood rating deteriorates. In contrast, root stocks were assessed mostly positive. The degree of decomposition also has an impact on the valuation with a clear gradient evident from negatively perceived images of fresh and beginning decomposition to positively evaluated stages of advanced and high decomposition.

Combining the results from the photologs with those of the post-trip interviews by conducting a logistic regression model allowed for testing the correlations between the respondents' attitudes towards deadwood and their actual valuation. The model showed that valuations of deadwood recorded in the photologs depend on photograph class, decomposition grade, age, ${ }^{2}$ gender, number of children, household income, but not on other socio-demographics like the level of education or the place of growing up. However, respondents with higher household income might also have a higher education level and therefore be more aware of the ecological importance of deadwood due to their higher knowledge and higher issue salience referring to nature (BMU and BfN 2010). Gundersen et al. (2017) found out

\footnotetext{
2 The positive relationship between age and deadwood evaluation in our study is contrary to the results of Job et al. (2019) for the general local population in the surroundings of Bavarian Forest National Park where especially people older than 65 show significantly higher resentment towards the (deadwood favoring) forest management in the National Park.
}

that information on deadwood's ecological benefits can increase the appreciation of deadwood. However, some influence of the socio-demographic characteristics can be determined regarding the deadwood assessment of the proposed item. Women see a higher amount of deadwood to be less associated with aesthetics. Pastorella et al. (2016) also conclude that the level of education, age and origin do not influence the preference for deadwood and its recreational value. They also note that gender and the cultural context play a role. These finding prove the necessity of adding a post-trip interview to the mere photograph shooting and valuation process. In this way, we got a deeper insight in the complexity of the respondents' deadwood perceptions.

Since many of the VEP participants came from the region, opinions and concerns about the deadwood situation in the original national park area may also have materialized in the interview. Because of severe storms and bark beetle outbreaks, the landscape has changed significantly more than in the study area (Michler et al. 2019). Müller et al. (2008) show that a strongly polarized range of opinions can be observed among their respondents. Some visitors believed that deadwood could be a sign of nature's destruction. These negative influences on the experience value may extend to the current study area. However, a more recent study by Job et al. (2019) show that related to the regrowth of forests in the older part of the national park and the much lower level of bark beetle infestations in the park the public perception of the national park forests improved considerably in the last decade. This makes the overall positive evaluation of deadwood in our study even more plausible.

Thus, the deadwood assessment at the Schwellsteig has generally been more positive in this study than in comparable ones (Liebecke et al. 2011). This is the result of multiple comparisons between landscape attributes. Nielsen et al. (2012), for example, have shown in their study of liked, disliked and unseen forest attributes that deadwood is one of the most disliked forest elements. In their study, only a fifth was marked as "liked". Also Tyrväinen et al. (2003) conclude that natural forest elements such as deadwood are not preferred, whereas Heyman's (2012) study shows that about the same number of deadwood photographs were "liked" as "not liked".

The present study is therefore one of the few that come to a more positive conclusion regarding deadwood. The VEP method provides an appropriate survey tool to investigate people's perceptions of forests and deadwood also in a rural context. Its exploratory character could be used for a first pilot study that should be followed by future research also outside protected areas, taking into account a larger geographical scale, representative sample and innovative methods for forest attribute evaluation, like discrete choice experiments, for instance. 
Acknowledgements Open Access funding provided by Projekt DEAL. This research was funded by the German Federal Ministry of Education and Research (BMBF) in the project "Biologische Vielfalt und Ökosystemleistungen von Wäldern mit Fokus auf Holz. Neue Wege der Nachhaltigen Nutzung im Spannungsfeld zwischen Ökologie, Ökonomie und Klimawandel (BioHolz)" (FKZ 01LC1323C). We also would like to thank Dr. Jürgen Meyerhoff for his inspiration to use this method/ approach.

Open Access This article is licensed under a Creative Commons Attribution 4.0 International License, which permits use, sharing, adaptation, distribution and reproduction in any medium or format, as long as you give appropriate credit to the original author(s) and the source, provide a link to the Creative Commons licence, and indicate if changes were made. The images or other third party material in this article are included in the article's Creative Commons licence, unless indicated otherwise in a credit line to the material. If material is not included in the article's Creative Commons licence and your intended use is not permitted by statutory regulation or exceeds the permitted use, you will need to obtain permission directly from the copyright holder. To view a copy of this licence, visit http://creativecommons.org/licenses/by/4.0/.

\section{References}

Arnberger A, Ebenberger M, Schneider IE, Cottrell S, Schlueter AC, von Ruschkowski E, Venette RC, Snyder SA, Gobster PH (2018) Visitor preferences for visual changes in bark beetle-impacted forest recreation settings in the United States and Germany. Environ Manag 61:209-223

Balomenou N, Garrod B (2014) Using volunteer-employed photography to inform tourism planning decisions: a study of St David's Peninsula, Wales. Tourism Manag 44:126-139

Balomenou N, Garrod B (2016) A review of participant generated image methods in the social sciences. J Mixed Methods Res 10(4):335-351

Brown TC, Daniel TC (1986) Predicting scenic beauty of timber stands. For Sci 32:471-487

Bundesministerium für Umwelt, Naturschutz und Reaktorsicherheit (BMU), Bundesamt für Naturschutz (BfN) 2010 Naturbewusstsein 2009. Berlin/Bonn

Carpaneto GM, Mazziotta A, Coletti G, Luiselli L, Audisio P (2010) Conflict between insect conservation and public safety: the case study of a saproxylic beetle (Osmoderma eremita) in urban parks. J Insect Conserv. https://doi.org/10.1007/s10841-010-9283-5

Cherem G (1973) Looking through the eyes of the public, or public images as social indicators of aesthetic opportunity. In: Brown PJ (ed) Proceedings, Aesthetics Opportunity Colloquium Utah, Utah State University, pp 52-64

Dakin S (2003) There's more to landscape than meets the eye: towards inclusive landscape assessment in resource and environmental management. Can Geogr 47(2): 185-200

Dorwart C, Moore R, Leung Y-F (2007) Visitor employed photography: its potential and use in evaluating visitors 'perceptions of resource impacts in trail and park settings. In Proceedings of the 2006 Northeastern Recreation Research Symposium, vol, 14, pp 307-315

Dorwart C, Moore R, Leung Y-F (2010) Visitors' perceptions of a trail environment and effects on experiences: a model for nature-based recreation experiences. Leisure Sci 32(1):33-54

Edwards DM, Jay M, Jensen FS, Lucas B, Marzano M, Montagné C, Peace A, Weiss G (2012a) Public preferences across Europe for different forest stand types as sites for recreation. Ecol Soc 17(1):27
Edwards DM, Jay M, Jensen FS, Lucas B, Marzano M, Montagne C, Peace A, Weiss G (2012b) Public preferences for structural attributes of forests: towards a pan-European perspective. For Policy Econ 19:12-19

Elsasser P (1996) Der Erholungswert des Waldes. Monetäre Bewertung der Erholungsleistung ausgewählter Wälder in Deutschland. J.D. Sauerländer's Verlag, Frankfurt am Main

Garbarino M, Marzano R, Shaw JD, Long JN (2015) Environmental drivers of deadwood dynamics in woodlands and forests. Ecosphere 6(3):1-24

Golivets M (2001) Aesthetic values of forest landscapes. Master thesis in Forest Management, Euroforester Master program, Swedish University of Agricultural Sciences Master Thesis no. 177 Southern Swedish Forest Research Centre Alnarp 2011

Gou S, Shibata S (2017) Using visitor-employed photography to study the visitor experience on a pilgrimage route - a case study of the Nakahechi Route on the Kumano Kodo pilgrimage network in Japan. J Outdoor Recreat Tourism 18:22-33

Gundersen V, Stange EE, Kaltenborn P, Vistad OI (2017) Public visual preferences for dead wood in natural boreal forests: the effects of added information. Landsc Urban Plan 158:12-24

Hauru K, Koskinen S, Kotze DJ, Lehvävirta S (2014) The effects of decaying logs on the aesthetic experience and acceptability of urban forests-implications for forest management. Landsc Urban Plan 123:114-123. https://doi.org/10.1016/j.landurbpla n.2013.12.014

Heyman E (2012) Analyzing recreational values and management effects in an urban forest with the visitor-employed photography method. Urban For Urban Green 11:267-277

Humphrey J, Bailey S (2012) Managing deadwood in forests and woodlands. Forestry Commission Practice Guide. Forestry Commission, Edinburgh. i-iv + 1-24 pp

Job H (2008) Estimating the regional economic impact of tourism to national parks: two case studies from Germany. GAIA 17(S1):134-142

Job H, Fließbach-Schendzielorz M, Bittlingmaier S, Herling A, Woltering M (2019) Akzeptanz der bayerischen Nationalparks. Ein Beitrag zum sozioökonomischen Monitoring in den Nationalparks Bayerischer Wald und Berchtesgaden (Würzburger Geographische Arbeiten 122). Würzburg University Press, Würzburg

Kaplan R, Kaplan S (1989) The experience of nature. A psychological perspective. Cambridge University Press, New York

Lee KC, Son YH (2017) Exploring landscape perceptions of Bukhansan National Park according to the degree of visitors' experience. Sustainability 9:1306

Levine B, Jensen K (2007) Around the world: the grand tour in photo albums. Princeton Architectural Press, New York

Liebecke R, Wagner K, Suda M (2011) Die Akzeptanz des Nationalparks Bayerischer Wald bei der lokalen Bevölkerung from https ://www.wup.wi.tum.de/fileadmin/w00beh/www/Files/Langfassun g_Akzeptanzstudie_NP_Bay_Wald.pdf

Loeffler TA (2004) A photo elicitation study of the meanings of outdoor adventure experiences. J Leisure Res 36(4):536-556

Mackay K, Couldwell C (2004) Using visitor-employed photography to investigate destination image. J Travel Res 42:390-396

Mayer M, Woltering M (2017) Nature tourism in Germany's protected areas. In: Chen JS, Prebensen NK (eds) Nature tourism. Routledge, Abingdon, pp 131-145

Meyer M, Rathmann J, Schulz C (2019) Spatially-explicit mapping of forest benefits and analysis of motivations for everyday-life's visitors on forest pathways in urban and rural contexts. Landsc Urban Plan 185:83-95

Michler T, Aschenbrand E, Leibl F (2019) Gestört, aber grün: 30 Jahre Forschung zu Landschaftskonflikten im Nationalpark Bayerischer Wald. In: Berr K, Jenal C (eds) Landschaftskonflikte. Springer, Wiesbaden, pp 291-311 
Müller J, Bütler R (2010) A review of habitat thresholds for dead wood: a baseline for management recommendations in European forests. Eur J For Res 129:981-992

Müller M, Job H (2009) Managing natural disturbance in protected areas: tourists' attitude towards the bark beetle in a German national park. Biol Conserv 142(2):375-383

Müller M, Mayer M, Job H (2008) Totholz und Borkenkäfer im Nationalpark Bayerischer Wald aus touristischer Perspektive. In: Job H (ed) Die Destination Nationalpark Bayerischer Wald als regionaler Wirtschaftsfaktor. Nationalpark Bayerischer Wald, Grafenau, pp $100-116$

Nielsen AB, Olsen SB, Lundhede T (2007) An economic valuation of the recreational benefits associated with nature-based forest management practices. Landsc Urban Plan 80(1-2):63-71

Nielsen AB, Heyman E, Richnau G (2012) Liked, disliked and unseen forest attributes: relation to modes of viewing and cognitive constructs. J Environ Manag 113:456-466

Ohe Y, Ikei H, Song C, Miyazaki Y (2017) Evaluating the relaxation effects of emerging forest-therapy tourism: a multidisciplinary approach. Tour Manag 62:322-334

Oku H, Fukamachi K (2006) The differences in scenic perception of forest visitors through their attributes and recreational activity. Landsc Urban Plan 75:34-42

Paletto A, Tosi V (2010) Deadwood density variation with decay class in seven tree species of the Italian Alps. Scand J For Res 25(2):164-173

Paletto A, Ferretti F, DeMeo I, Cantiani P, Focacci M (2012) Ecological and environmental role of deadwood in managed and unmanaged forests. In: Diez JJ (ed) Sustainable forest management-current research, pp 219-238

Paletto A, Guerrini S, De Meo I (2017) Exploring visitors' perceptions of silvicultural treatments to increase the destination attractiveness of peri-urban forests: a case study in Tuscany Region (Italy). Urban For Urban Green 27:314-323

Pastorella F, Avdagic A, Čabaravdic A, Mrakovic A, Osmanovic M, Paletto A (2016) Tourists' perception of deadwood in mountain forests. Ann For Res 59(2):311-326

Qiu L, Lindberg S, Busse Nielsen A (2013) Is biodiversity attractive? On-site perception of recreational and biodiversity values in urban green space. Landsc Urban Plan 119:136-146
Sacher P, Kaufmann S, Mayer M (2017) Wahrnehmung der natürlichen Waldentwicklung im Nationalpark Harz durch Besucher. Eine Befragung an Standorten mit unterschiedlicher Totholzexposition. Naturschutz und Landschaftsplanung 49(9):291-299

Seibold S, Bässler C, Brandl R, Büche B, Szallies A, Thorn S, Ulyshen MD, Müller J (2016) Microclimate and habitat heterogeneity as the major drivers of beetle diversity in dead wood. J Appl Ecol 53:934-943

Takayama N, Korpela K, Lee J, Morikawa T, Tsunetsugu Y, Park BJ, Li Q, Tyrväinen L, Miyazaki Y, Takahide Kagawa T (2014) Emotional, restorative and vitalizing effects of forest and urban environments at four sites in Japan. Int J Environ Res Public Health 11:7207-7230

Taye FA, Abildtrup J, Mayer M, Ščasný M, Strange N, Lundhede T (2019) Childhood experience in forest recreation practices: evidence from nine European countries. Urban For Urban Green 46:126471. https://doi.org/10.1016/j.ufug.2019.126471

Taylor J, Czarnowski K, Sexton N, Flick S (1995) The importance of water to Rocky Mountain National Park visitors: an adaptation of visitor-employed photography to natural resources management. J Appl Recreat Res 20(1):61-85

Tyrväinen L, Silvennoinen H, Kolehmainen O (2003) Ecological and aesthetic values in urban forest management. Urban For Urban Green 1(3):135-149

Von Ruschkowski E, Mayer M (2011) From conflict to partnership? Interactions between protected areas, local communities and operators of tourism enterprises in two German National Park Regions. J Tourism Leisure Stud 17(2):147-181

Wagner K, Suda M (2008) Erholung zwischen toten Bäumen. From http://www.ufz.de/export/data/36/41666_Muench_wagner.pdf

Wallner P, Kundi M, Arnberger A, Eder R, Allex B, Weitensfelder L, Hutte H-P (2018) Reloading pupils' batteries: impact of green spaces on cognition and wellbeing. Int J Environ Res Public Health 15(6):1205. https://doi.org/10.3390/ijerph15061205

Publisher's Note Springer Nature remains neutral with regard to jurisdictional claims in published maps and institutional affiliations. 